\title{
Implementasi Metode Regresi Linier Berganda Untuk Proyeksi Kebutuhan Listrik Dalam Rangka Analisis Strategi Bisnis Di PT XYZ
}

\author{
Fadhli Farsa \\ Magister Teknik Elektro, Sekolah Tinggi Teknik PLN \\ fadhli_farsa@ymail.com
}

\begin{abstract}
Electrical energy requirements in the Industrial Estate should be fulfilled as a supporting industry in the region in order to develop. Therefore, one of PT XYZ's corporate strategies is to do demand forecasting. In this study, the authors will use multiple regression linear methods and compared with Sectoral quantitative forecasting methods from 2018 to 2022. The dependent variable used is the consumption of electrical energy in each sector (industry, business, housing and general) and for independent variables is the total of PT XYZ GDP, Dollar Exchange, PT XA Production, Number of Consumers, Cilegon GRDP, Growth Rate, Contract Power, Cilegon Export \& Import, Indonesian Economic Growth. Based on forecasting results using multiple linear regression methods obtained in 2022 the need for electrical energy is 824,252 GWh down by 9.1\% from 2017 and compared with the Sectoral quantitative forecasting method 946 GWh increased by $4.3 \%$ from 2017, while the average load with the new consumer plan in 2019 - 2021 then the total load in 2022 is $158.61 \mathrm{MW}$, while the final results from the SWOT analysis show that PT XYZ is in quadrant 1, the strategy is Progressive and in Porter's Five Force's it is found that the average value is 3 which means the industry is still attractive.
\end{abstract}

Keywords: Multiple Linear Regression, Sectoral Quantitative Forecasting, Porter's Five Forces, SWOT Analysis, PESTLE Analysis

\begin{abstract}
ABSTRAK
Kebutuhan energi listrik di Kawasan Industri harusnya dapat dipenuhi sebagai pendukung industri di kawasan tersebut agar dapat berkembang. Oleh karena itu, salah satu strategi perusahaan PT $X Y Z$ adalah dengan melakukan demand forecasting. Pada penelitian ini, penulis akan menggunakan metode linier multiple regression dan dibandingkan dengan metode peramalan kuantitatif Sektoral dari 2018 hingga tahun 2022. Adapun variabel dependen yang digunakan adalah penggunaan energi listrik pada masing - masing sektor (industri, bisnis, perumahan dan umum) dan untuk variabel bebas nya adalah total PDRB PT XYZ, Kurs Dollar, Produksi PT XA, Jumlah Konsumen, PDRB Cilegon, Laju Pertumbuhan, Daya Kontrak, Eskpor \& Impor Cilegon, Pertumbuhan Ekonomi Indonesia. Berdasarkan hasil peramalan menggunakan metode regresi linier berganda didapatkan pada tahun 2022 kebutuhan energi listrik adalah sebesar 824,252 GWh turun sebesar 9,1\% dari tahun 2017 dan dibandingkan dengan metode peramalan kuantitatif Sektoral 946 GWh naik sebesar 4,3\% dari tahun 2017, sedangkan rata - rata beban dengan adanya rencana konsumen baru di tahun 2019 - 2021 maka total beban pada tahun 2022 adalah sebesar 158,61 MW, adapun hasil akhir dari Analisa SWOT didapatkan bahwa PT XYZ berada pada kuadran 1 yaitu strateginya adalah Progressive dan pada Porter's Five Force's didapatkan bahwa rata - rata nilai adalah 3 yang berarti industri masih atraktif.
\end{abstract}

Kata kunci: Regresi Linier Berganda, Peramalan Kuantitatif Sektoral, Porter's Five Force's, SWOT Analysis, PESTLE Analysis 


\section{PENDAHULUAN}

Kawasan industri merupakan salah satu hak veto yang diberikan Kementrian ESDM untuk dapat menyuplai listrik dengan mendapatkan IUPTL (Izin Usaha Penyediaan Tenaga Listrik). Oleh Karena itu, potensi penjualan listrik sangat bergantung dari pertumbuhan demand di kawasan yang merupakan wilayah penjualan listrik.

Strategi bisnis merupakan salah satu faktor kesuksesan dalam berbisnis listrik, mulai dari Demand Forecasting baik melakukan peramalan berdasarkan history, maupun berdasarkan luasan Kawasan Industri yang menjadikan potensi konsumen yang tergambarkan dari luasan. Belum adanya analisa terhadap proyeksi demand pada PT XYZ merupakan salah satu alasan penulis mengambil proyeksi demand ini dan mencoba memberikan gambaran posisi PT XYZ berdasarkan beberapa analisa bisnis. Penulis akan menggunakan Metode Regresi Linier Berganda dibandingkan dengan Metode Peramalan Kuantitatif Sektoral dan akan dibagi menjadi 4 segmentasi yaitu segmen industri (industri PT XA dan industri umum), segmen umum, segmen bisnis dan segmen perumahan. Hal ini dilakukan untuk menentukan berapa kebutuhan pembangkit yang akan diinvestasikan, pemilihan investasi pembangkit, atau strategi fokus pada jasa dengan melakukan kerjasama dengan PLN sebagai penyuplai listrik.

Banyak metode yang dapat digunakan dalam rangka melakukan demand forecasting seperti, metode sampling statistik, metode ekstrapolasi, metode perbandingan, metode end user. Pemilihan metode regresi linier berganda dipilih karena dapat menganalisa dari beberapa variabel (PDRB PT XYZ per segmen, Kurs Dollar, Produksi PT XA, Jumlah Konsumen, PDRB Kota Cilegon, Laju Pertumbuhan, Daya Kontrak Konsumen, Eskpor \& Impor Kota Cilegon, Pertumbuhan Ekonomi Indonesia) yang akan digunakan dan seberapa berpengaruhkah variabel tersebut terhadap penggunaan energi.

Adapun analisa bisnis yang digunakan secara eksternal adalah Porter's Five Force's (untuk mengetahui seberapa atraktif suatu bisnis) dan PESTLE (Politic, Economic, Social, Technology, Legal, Environment) Analysis (untuk mengetahui isu - isu yang berpengaruh baik secara politik, ekonomi, social, teknologi, legal dan lingkungan) dan secara internal adalah SWOT (Strength, Weakness, Opportunities, Threat) Analysis (untuk mengetahui kekuatan, kelemahan, kesempatan, ancaman dan posisi suatu organisasi dengan membaginya menjadi 4 kuadran).

\section{METODE/PERANCANGAN PENELITIAN}

\subsection{Kerangka Berfikir}

Multiple Regression merupakan salah satu tools untuk membantu dalam meramalkan dan melihat pengaruh suatu variabel dependen terhadap beberapa variabel bebas. Setelah mendapatkan proyeksi kedepan, maka akan dibuatkan strategi bisnis dengan menganalisa secara eksternal maupun internal. Berikut merupakan alur kerangka berfikir yang ditetapkan oleh penulis:

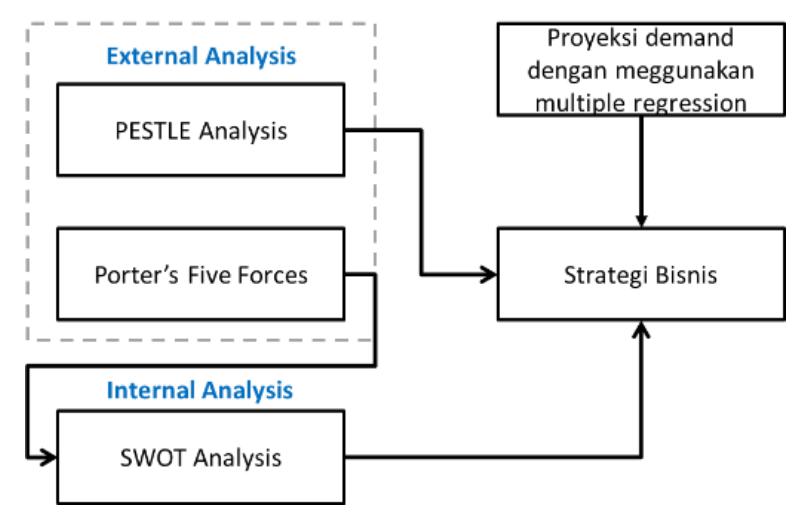

Gambar 1. Kerangka Berfingkir 


\section{KILAT}

\subsection{Metode Penelitian}

Berdasarkan permasalahan yang sedang dilakukan penelitian, ada beberapa pendekatan metode yang digunakan dalam proses penelitian ini adalah menggunakan pendekatan kuantitatif. Pendekatan kuantitatif ini meneliti secara sistematis penentuan strategi berdasarkan beberapa analisa dan demand forecasting. Data yang diambil adalah data dari Annual Report, Data statistik oleh BPS, Data dari pengelola Kawasan Industri, Data pemakaian energi konsumen setiap segmen, Data Kurs Dolar dari BI.

Untuk pendekatan strategi bisnis menggunakan beberapa analisa baik secara eksternal maupun internal yang merupakan pendukung untuk penentuan strategi perusahaan. Adapun alur metode penelitian dapat dilihat pada Gambar 1 berikut ini.

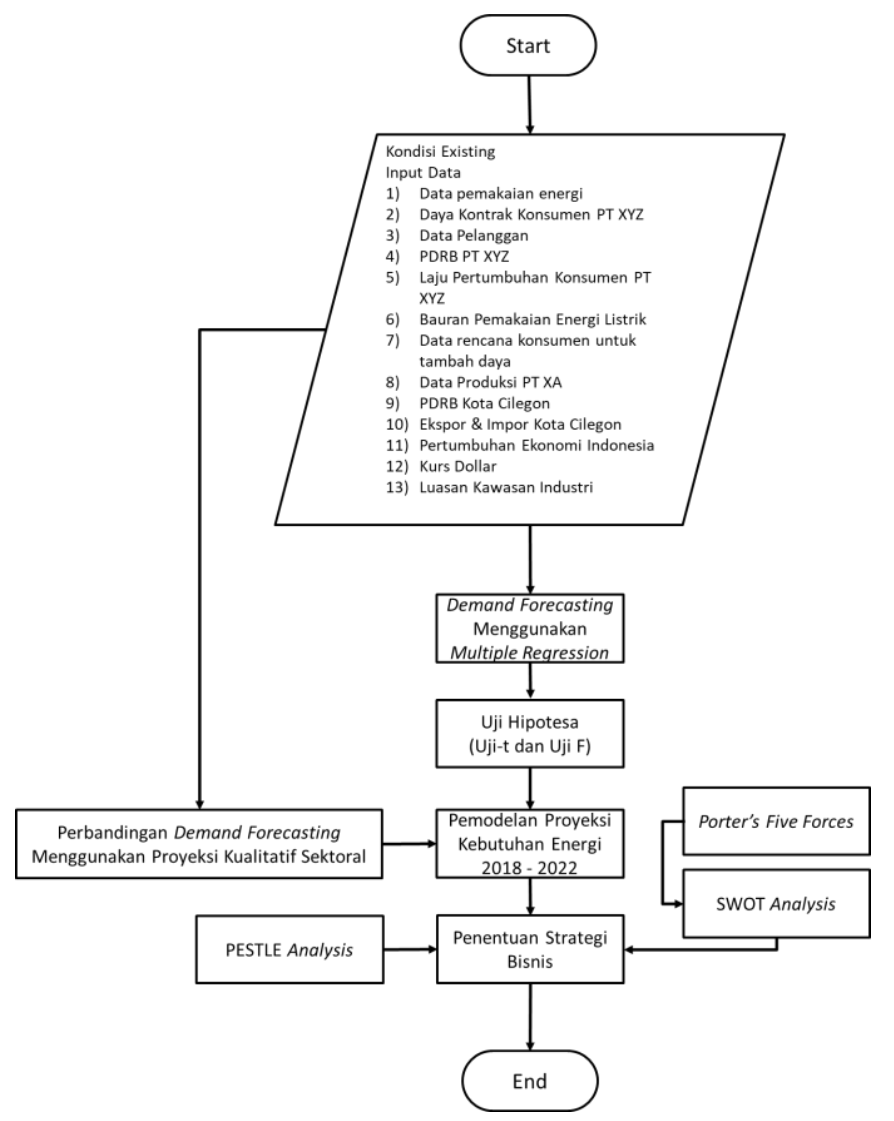

Gambar 2. Metodologi Penelitian

\section{HASIL DAN PEMBAHASAN}

3.2. Demand Forecasting Menggunakan Multiple Regression Method

\subsubsection{Segmen Industri}

Tabel 1. Hasil Regresi di Segmen Industri PT XA

\begin{tabular}{lrrrrrr}
\hline & Coefficients & Standard Error & \multicolumn{1}{c}{ t Stat } & \multicolumn{1}{c}{ P-value } & & \\
\cline { 1 - 5 } Intercept & 1070142,04 & 1325032,595 & 0,807634502 & 0,455988717 & & Regression Statistics \\
Produksi XA & 0,265466828 & 0,053223347 & 4,987789054 & 0,004147899 & Multiple R & 0,991738662 \\
Persentase PDRB Industri KDL & 220756,6824 & 266055,0492 & 0,829740623 & 0,444481258 & R Square & 0,983545574 \\
Kurs Dollar & $-62,11607079$ & 69,64939435 & $-0,891839353$ & 0,413335026 & Adjusted R Squa & 0,967091148 \\
Pertumbuhan Ekonomi Indonesia & $-8043706,547$ & 11012543,99 & $-0,730413114$ & 0,4979098 & Standard Error & 114857,8728 \\
Ekspor Kota Cilegon & 17,43800806 & 58,10097802 & 0,30013278 & 0,776153489 & Observations & 11 \\
\hline
\end{tabular}


Didapatkan persamaanya sebagai berikut:

$$
Y=0,2655_{x 1}+220756,6824_{x 2}-62,116_{x 3}-8043706,547_{x 4}+17,438_{x 5}+1070142,04
$$

Dimana:

$\mathrm{x} 1=$ Produksi PT XA; $\mathrm{x} 2=$ Persentase PDRB Industri PT XYZ ; $\mathrm{x} 3=$ Kurs Dollar ; $\mathrm{x} 4=$ Pertumbuhan Ekonomi Indonesia ; $55=$ Ekspor Kota Cilegon

Dari persamaan di atas didapatkan bahwa yang mempengaruhi konsumsi energi listrik Industri XA adalah produksi PT XA, persentase PDRB Industri PT XYZ dan ekspor Kota Cilegon.

Tabel 2. Hasil Regresi di Segmen Industri Umum

\begin{tabular}{|c|c|c|c|c|c|c|c|c|c|c|}
\hline & Coefficients & Standard Error & $t$ Stat & $P$-value & Lower 95\% & Upper 95\% & Lower $99,0 \%$ & Upper $99,0 \%$ & & \\
\hline Intercept & $-70764,23807$ & 44498,45339 & $-1,590262867$ & 0,186982007 & $-194311,7512$ & 52783,27504 & $-275639,3391$ & 134110,863 & \multicolumn{2}{|c|}{ Regression Statistics } \\
\hline Jumlah Konsumen & 1234,369449 & 683,9517656 & 1,804760965 & 0,145430634 & $-664,5850832$ & 3133,323981 & $-1914,609368$ & 4383,348265 & 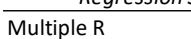 & 0,998004398 \\
\hline PDRB Kota Cilegon & $-0,001973257$ & 0,000456703 & $-4,320658514$ & 0,012440946 & $-0,003241268$ & $-0,000705247$ & $-0,00407596$ & 0,000129446 & $R$ Square & 0,996012778 \\
\hline Kurs Dollar & $-2,808176638$ & 4,157586792 & $-0,675434279$ & 0,536433379 & $-14,35148814$ & 8,73513486 & $-21,95010067$ & 16,33374739 & $\begin{array}{l}\text { R Square } \\
\text { Adjusted R Square }\end{array}$ & 0,990031946 \\
\hline Ekspor Kota Cilegon & 5,899830685 & 4,769481503 & 1,23699624 & 0,283747655 & $-7,342372889$ & 19,14203426 & $-16,05931464$ & 27,85897601 & Standard Error & 7373,015186 \\
\hline Impor Kota Cilegon & 10,2157489 & 2,00512256 & 5,094825177 & 0,007007832 & 4,648636186 & 15,78286162 & 0,983974408 & 19,4475234 & tandard trror & 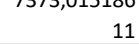 \\
\hline Daya Kontrak & 0,53094916 & 0,185393366 & 2,863905927 & & 0,016214656 & 1,045683663 & $-0,322619486$ & 1,384517805 & & \\
\hline
\end{tabular}

Didapatkan persamaanya sebagai berikut:

$$
\begin{gathered}
Y=1234,36945 x_{1}-0,00197 x_{2}-2,8082 x_{3}+5,899 x_{4}+10,2157 x_{5}+0,531 x_{6} \\
-70764,23807
\end{gathered}
$$

Dimana :

x1 = Jumlah Konsumen; $\mathrm{x} 2=$ PDRB Kota Cilegon ; x3 = Kurs Dollar ; 4 = Ekspor Kota Cilegon ; x5 = Impor Kota Cilegon ; 6 = Daya Kontrak

Dari persamaan di atas didapatkan bahwa yang mempengaruhi konsumsi energi listrik Industri Umum adalah Jumlah konsumen, ekspor Kota Cilegon, impor Kota Cilegon dan daya kontrak.

\begin{tabular}{|c|c|c|c|c|c|c|}
\hline & Coefficients & Standard Error & t Stat & $P$-value & \multicolumn{2}{|c|}{ Regression Statistics } \\
\hline Intercept & 6608,3133 & 2539,378384 & 2,602335037 & 0,035304958 & Multiple R & 0,959317561 \\
\hline Jumlah Pelanggan & 24,37778 & 32,63025462 & 0,747091317 & 0,47934583 & R Square & 0,920290183 \\
\hline Kurs Dollar & $-0,485302$ & 0,307816913 & $-1,576594046$ & 0,158894003 & ljusted R Squ & 0,886128833 \\
\hline Daya Kontrak & 0,5293167 & 0,171161054 & 3,092506902 & 0,017505305 & $\begin{array}{l}\text { Standard trror } \\
\text { Observations }\end{array}$ & $\begin{array}{r}595,2872507 \\
11\end{array}$ \\
\hline
\end{tabular}

\subsubsection{Segmen Bisnis}

Tabel 3. Hasil Regresi di Segmen Bisnis

Didapatkan persamaanya sebagai berikut:

$$
Y=26,378 x_{1}-0,485 x_{2}+0,529 x_{3}+6608,3133
$$

Dimana:

$\mathrm{x} 1=$ Jumlah Konsumen $; \mathrm{x} 2=$ Kurs Dollar $; \mathrm{x} 3=$ Daya Kontrak

Dari persamaan di atas didapatkan bahwa yang mempengaruhi konsumsi energi listrik segmen bisnis adalah Jumlah konsumen dan daya kontrak. 


\subsubsection{Segmen Umum}

Tabel 4. Hasil Regresi di Segmen Umum

\begin{tabular}{|c|c|c|c|c|c|c|}
\hline & Coefficients & Standard Error & $t$ Stat & $P$-value & & \\
\hline Intercept & $-5814,291096$ & 641,3507949 & $-9,065695627$ & 0,01194974 & & \\
\hline Jumlah Konsumen & 21,0360831 & 2,630483096 & 7,997041732 & 0,015279113 & \multicolumn{2}{|c|}{ Regression Statistics } \\
\hline PDRB Kota Cilegon & $\begin{array}{l}-2,57708 \mathrm{E}-06 \\
-6541081056\end{array}$ & 1,51312E-06 & $\begin{array}{l}-1,703154944 \\
-4,404158388\end{array}$ & $\begin{array}{l}0,230650862 \\
0,047882752\end{array}$ & Multiple R & 0,999718584 \\
\hline $\begin{array}{l}\text { Persentase P } \\
\text { Kurs Dollar }\end{array}$ & $\begin{array}{r}-654,1081056 \\
0,167653105\end{array}$ & $\begin{array}{l}148,5205681 \\
0,031773706\end{array}$ & $\begin{array}{r}-4,404158388 \\
5,276473157\end{array}$ & $\begin{array}{r}0,04 / 882 / 52 \\
0,03409188\end{array}$ & R Square & 0,999437247 \\
\hline Pertumbuhan Ekon & 12343,90016 & 3532,048783 & 3,494827202 & 0,073020041 & Adjusted R Square & 0,997186236 \\
\hline Ekspor & 0,56731284 & 0,035380177 & 16,03476548 & 0,003866786 & Standard Error & 22,71693131 \\
\hline $\begin{array}{l}\text { Impor } \\
\text { Daya Kontrak }\end{array}$ & $\begin{array}{r}-0,055832628 \\
2,630786415\end{array}$ & $\begin{array}{l}0,007864069 \\
0,170986691\end{array}$ & $\begin{array}{r}-7,09971202 \\
15,38591333\end{array}$ & $\begin{array}{l}0,019267434 \\
0,004197707\end{array}$ & Observations & 11 \\
\hline
\end{tabular}

Didapatkan persamaanya sebagai berikut:

$$
\begin{gathered}
Y=21,036 x_{1}-0,00000257 x_{2}-654,1081 x_{3}+0,1677 x_{4}+12343,9 x_{5}+0,567 x_{6} \\
-0,0558 x_{7}+2,6308 x_{8}-5814,29
\end{gathered}
$$

Dimana:

x1 = Jumlah Konsumen; $\mathrm{x} 2=$ PDRB Kota Cilegon ; $\mathrm{x} 3=$ Persentase PDRB Industri XYZ; $\mathrm{x} 4=$ Kurs Dollar; x5 = Pertumbuhan Ekonomi Indonesia; x6 = Ekspor Kota Cilegon; x7 = Impor Kota Cilegon; $\mathrm{x} 8$ = Daya Kontrak

Dari persamaan di atas didapatkan bahwa yang mempengaruhi konsumsi energi listrik Segmen Umum adalah Jumlah konsumen, kurs dollar, pertumbuhan ekonomi Indonesia, ekspor Kota Cilegon dan daya kontrak.

\subsubsection{Segmen Perumahan}

\begin{tabular}{|c|c|c|c|c|c|c|}
\hline & Coefficients & Standard Error & t Stat & P-value & & \\
\hline Intercept & $-298365,5$ & 93303,8046 & $-3,197784974$ & 0,04941553 & \multirow{2}{*}{\multicolumn{2}{|c|}{ Regression Statistics }} \\
\hline Jumlah Penduduk & 27,471573 & 18,54325519 & 1,481485986 & 0,235075184 & & \\
\hline Produksi PT XA & 0,0021519 & 0,001164276 & 1,848278401 & 0,16170108 & Multiple R & 0,9611865 \\
\hline Daya Kontrak & 8,080653 & 2,964824508 & 2,725508043 & 0,072213339 & R Square & 0,9238794 \\
\hline PDRB Kota Cilegon & $-0,00025$ & 0,00010836 & $-2,309586551$ & 0,10407037 & Adjusted R Squa & 0,7462647 \\
\hline Persentase PDRB KDL & $-669,6748$ & 248,9449962 & $-2,690051237$ & 0,074410924 & andard Error & 1106,6117 \\
\hline Kurs Dollar & 4,0563443 & 1,505134745 & 2,695004065 & 0,074099018 & & \\
\hline Laju Pertumbuhan Penduduk & 150689,89 & 33312,01058 & 4,523590222 & 0,020204309 & Observations & 11 \\
\hline
\end{tabular}

Tabel 5. Hasil Regresi di Segmen Perumahan

Didapatkan persamaanya sebagai berikut:

$$
\begin{gathered}
Y=27,472 x_{1}+0,002152 x_{2}+8,08065 x_{3}-0,00025 x_{4}-669,675 x_{5}+4,056 x_{6} \\
+150689,89 x_{7}-298365,5
\end{gathered}
$$

Dimana:

x1 = Jumlah Penduduk ; x2 = Produksi PT XA ; x3 = Daya Kontrak; x4 = PDRB Kota Cilegon ; x5 = Persentase PDRB XYZ; x6 = Kurs Dollar ; x7 = Laju Pertumbuhan;

Dari persamaan di atas didapatkan bahwa yang mempengaruhi konsumsi energi listrik Segmen Perumahan adalah Jumlah penduduk, produksi PT XA, daya kontrak, kurs dollar dan laju pertumbuhan. 


\subsection{Uji Hipotes (Uji-T dan Uji F)}

$\mathrm{H}_{0}$ diterima bila $\mathrm{F}_{\text {hitung }}<\mathrm{F}_{\text {tabel }} ; \mathrm{H}_{0}$ ditolak bila $\mathrm{F}_{\text {hitung }}>\mathrm{F}_{\text {tabel }}, \mathrm{H}_{0}$ Tidak ada pengaruh secara signifikan antara variabel $\mathrm{X}_{1}-\mathrm{Xn}, \mathrm{H} 1$ Ada pengaruh secara signifikan antara variabel $\mathrm{X}_{1}-\mathrm{X}_{\mathrm{n}}$

\subsubsection{Segmen Industri}

\section{a. Industri XA (Pelanggan Terbesar)}

Tabel 6. Tabel Anova Segmen Industri XA

\begin{tabular}{lrrrrr}
\hline & $d f$ & \multicolumn{1}{c}{$S S$} & \multicolumn{1}{c}{$M S$} & $F$ & Significance $F$ \\
\hline Regression & 5 & $3,94279 \mathrm{E}+12$ & $7,88557 \mathrm{E}+11$ & 59,77392233 & 0,000185356 \\
Residual & 5 & 65961654753 & 13192330951 & & \\
Total & 10 & $4,00875 \mathrm{E}+12$ & & & \\
\hline
\end{tabular}

Uji Koefisien Regresi secara Bersama - sama (Uji F)

F hitung $=59,77392$

$\mathrm{F}$ tabel $=5,050329$

Didapatkan bahwa Fhitung > Ftabel maka H0 ditolak, artinya adalah ada pengaruh secara signifikan antara variabel X1-X5, Kemudian kita uji secara parsial (Uji t)

Tabel 7. Tabel Perhitungan Parsial Variabel Segmen Industri XA

\begin{tabular}{lccccc} 
& \multicolumn{1}{c}{$\mathrm{x} 1$} & $\mathrm{x} 2$ & $\mathrm{x} 3$ & $\mathrm{x} 4$ & $\mathrm{x} 5$ \\
\cline { 2 - 6 } T Hitung & 4,987789054 & 0,829740623 & $-0,891839353$ & $-0,730413114$ & 0,30013278 \\
T Tabel & 3,16338145 & 3,16338145 & 3,16338145 & 3,16338145 & 3,16338145 \\
\cline { 2 - 7 } & H0 ditolak & H0 diterima & H0 diterima & H0 diterima & H0 diterima
\end{tabular}

Dari hasil di atas didapatkan bahwasanya, hanya variable X1 saja yang mengalami penolakan H0 yang artinya bahwa secara parsial ada pengaruh signifikan antara Produksi PT XA dengan Pemakaian Energi.

\section{b. Industri Umum}

Tabel 8. Tabel Anova Segmen Industri Umum

\begin{tabular}{|c|c|c|c|c|c|}
\hline & $d f$ & SS & $M S$ & $F$ & Significance $F$ \\
\hline Regression & 6 & 54318126151 & 9053021025 & 166,5341375 & 9,48813E-05 \\
\hline Residual & 4 & 217445411,7 & 54361352,93 & & \\
\hline Total & 10 & 54535571563 & & & \\
\hline
\end{tabular}

Uji Koefisien Regresi secara Bersama - sama (Uji F)

F hitung $=166,5341$

$\mathrm{F}$ tabel $=6,163132$

Didapatkan bahwa Fhitung > Ftabel maka H0 ditolak, artinya adalah ada pengaruh secara signifikan antara variabel X1-X6, Kemudian kita uji secara parsial (Uji t)

Tabel 9. Tabel Perhitungan Parsial Variabel Segmen Industri Umum

\begin{tabular}{lcccccc} 
& \multicolumn{1}{c}{$\mathrm{x} 1$} & $\mathrm{x} 2$ & $\mathrm{x3}$ & $\mathrm{x} 4$ & $\mathrm{x} 5$ & $\mathrm{x6}$ \\
\cline { 2 - 7 } T Hitung & 1,80476097 & $-4,3206585$ & $-0,6754343$ & 1,23699624 & 5,09482518 & 2,86390593 \\
T Tabel & 3,49540593 & 3,49540593 & 3,49540593 & 3,49540593 & 3,49540593 & 3,49540593 \\
\cline { 2 - 7 } & H0 diterima & H0 ditolak & H0 diterima & HO diterima & H0 ditolak & H0 diterima
\end{tabular}




\section{KILAT}

Vol. 8, No. 2, Oktober 2019, P-ISSN 2089-1245, E-ISSN 2655-4925

Dari hasil di atas didapatkan bahwasanya, variable X2 dan X5 saja yang mengalami penolakan H0 yang artinya bahwa secara parsial ada pengaruh signifikan antara PDRB Kota Cilegon dan Impor Kota Cilegon dengan Pemakaian Energi.

\subsubsection{Segmen Umum}

Tabel 10. Tabel Anova Segmen Umum

\begin{tabular}{|c|c|c|c|c|c|}
\hline & $d f$ & SS & MS & $F$ & Significance $F$ \\
\hline Regression & 8 & 1833020,124 & 229127,5155 & 443,9948332 & 0,002249112 \\
\hline Residual & 2 & 1032,117936 & 516,0589681 & & \\
\hline Total & 10 & 1834052,242 & & & \\
\hline
\end{tabular}

Uji Koefisien Regresi secara Bersama - sama (Uji F)

$\mathrm{F}$ hitung $=443,995$

$\mathrm{F}$ tabel $=240,543$

Didapatkan bahwa Fhitung > Ftabel maka H0 ditolak, artinya adalah ada pengaruh secara signifikan antara variabel X1-X8, Kemudian kita uji secara parsial (Uji t)

Tabel 11. Tabel Perhitungan Parsial Variabel Segmen Umum

\begin{tabular}{|c|c|c|c|c|c|c|c|c|}
\hline & $x 1$ & $x 2$ & $x 3$ & $x 4$ & $\times 5$ & $x 6$ & $x 7$ & $x 8$ \\
\hline & 7,99704173 & $-1,7031549$ & $-4,4041584$ & 5,27647316 & 3,4948272 & 16,0347655 & $-7,099712$ & 15,3859133 \\
\hline \multirow[t]{2}{*}{ T Tabel } & 6,20534682 & 6,20534682 & 6,20534682 & 6,20534682 & 6,20534682 & 6,20534682 & 6,20534682 & 6,20534682 \\
\hline & HO ditolak & HO diterima & HO diterima & H0 diterima & HO diterima & HO ditolak & HO ditolak & HO ditolak \\
\hline
\end{tabular}

Dari hasil di atas didapatkan bahwasanya, variable X1, X6, X7 dan X8 saja yang mengalami penolakan $\mathrm{H} 0$ yang artinya bahwa secara parsial ada pengaruh signifikan antara Jumlah Konsumen, Ekspor Kota Cilegon, Impor Kota Cilegon dan Daya Kontrak dengan Pemakaian Energi.

\subsubsection{Segmen Bisnis}

Tabel 12. Tabel Anova Segmen Bisnis

\begin{tabular}{|c|c|c|c|c|c|}
\hline & $d f$ & SS & $M S$ & $F$ & Significance $F$ \\
\hline Regression & 3 & 28639417,62 & 9546472,539 & 26,93951451 & 0,000322406 \\
\hline Residual & 7 & 2480568,376 & 354366,9109 & & \\
\hline Total & 10 & 31119985,99 & & & \\
\hline
\end{tabular}

Uji Koefisien Regresi secara Bersama - sama (Uji F)

$\mathrm{F}$ hitung $=26,9395$

F tabel $=4,3468$

Didapatkan bahwa Fhitung > Ftabel maka H0 ditolak, artinya adalah ada pengaruh secara signifikan antara variabel X1-X3, Kemudian kita uji secara parsial (Uji t)

Tabel 13. Tabel Perhitungan Parsial Variabel Segmen Bisnis

\begin{tabular}{lccc}
\cline { 2 - 4 } T Hitung & $\mathrm{x} 1$ & $\mathrm{x} 2$ & $\mathrm{x} 3$ \\
\cline { 2 - 4 } T Tabel & 0,7470913 & $-1,576594$ & 3,0925069 \\
& 2,8412442 & 2,8412442 & 2,8412442 \\
\cline { 2 - 4 } & H0 diterima & H0 diterima & H0 ditolak
\end{tabular}

Dari hasil di atas didapatkan bahwasanya, hanya variable X3 saja yang mengalami penolakan HO yang artinya bahwa secara parsial ada pengaruh signifikan antara Daya Kontrak dengan Pemakaian Energi. 


\subsubsection{Segmen Perumahan}

Tabel 14. Tabel Anova Segmen Perumahan

\begin{tabular}{lrcccr}
\hline & $d f$ & $S S$ & $M S$ & $F$ & Significance $F$ \\
\hline Regression & 7 & 44588706,19 & 6369815,171 & 5,201591968 & 0,10159011 \\
Residual & 3 & 3673768,652 & 1224589,551 & & \\
Total & 10 & 48262474,85 & & & \\
\hline
\end{tabular}

Uji Koefisien Regresi secara Bersama - sama (Uji F)

F hitung $=5,2016$

$\mathrm{F}$ tabel $=6,163132$

Didapatkan bahwa Fhitung < Ftabel maka H0 diterima, artinya adalah tidak ada pengaruh secara signifikan antara variabel X1-X7, Kemudian kita uji secara parsial (Uji t).

Tabel 15. Tabel Perhitungan Parsial Variabel Perumahan

\begin{tabular}{lccccccc} 
& \multicolumn{1}{c}{ x1 } & x2 & x3 & x4 & x5 & x6 & x7 \\
\cline { 2 - 7 } T Hitung & 1,48148599 & 1,8482784 & 2,72550804 & $-2,3095866$ & $-2,6900512$ & 2,69500407 & 4,52359022 \\
T Tabel & 4,17653485 & 4,17653485 & 4,17653485 & 4,17653485 & 4,17653485 & 4,17653485 & 4,17653485 \\
\cline { 2 - 7 } & H0 diterima & H0 diterima & H0 diterima & H0 diterima & H0 diterima & HO diterima & H0 ditolak
\end{tabular}

Dari hasil di atas didapatkan bahwasanya, hanya variable X7 saja yang mengalami penolakan H0 yang artinya bahwa secara parsial ada pengaruh signifikan antara Laju Pertumbuhan Penduduk dengan Pemakaian Energi.

\subsection{Proyeksi Menggunakan Peramalan Kualitatif Sektoral}

\subsubsection{Segmen Industri}

\begin{tabular}{|c|c|c|c|c|}
\hline & $\begin{array}{l}\text { Jumlah } \\
\text { Konsumen }\end{array}$ & $\begin{array}{l}\text { Kebutuhan Energi } \\
\text { (MWh) }\end{array}$ & $\begin{array}{l}\text { Elastisitas } \\
\text { Konsumen }\end{array}$ & $\begin{array}{c}\text { Persentase } \\
\text { PDRB/ Kapita (\%) }\end{array}$ \\
\hline 2018 & 323 & $878.993,63$ & 0,17255617 & $1,42 \%$ \\
\hline 2019 & 324 & $881.149,21$ & 0,17255617 & $1,42 \%$ \\
\hline 2020 & 324 & $883.310,08$ & 0,17255617 & $1,42 \%$ \\
\hline 2021 & 325 & $885.476,24$ & 0,17255617 & $1,42 \%$ \\
\hline 2022 & 326 & $887.647,71$ & 0,17255617 & $1,42 \%$ \\
\hline
\end{tabular}

Berdasarkan tabel di atas, akan ada kenaikan 1,23\% dalam konsumsi pemakaian energi oleh Segmen Industri hingga tahun 2022 mencapai 887.647,71 MWh. 


\section{KILAT}

Vol. 8, No. 2, Oktober 2019, P-ISSN 2089-1245, E-ISSN 2655-4925

\subsubsection{Segmen Bisnis}

Tabel 17. Proyeksi Kualitatif Sektoral di Segmen Bisnis

\begin{tabular}{|r|r|r|c|c|}
$\begin{array}{c}\text { Jumlah } \\
\text { Konsumen }\end{array}$ & $\begin{array}{r}\text { Kebutuhan Energi } \\
\text { (MWh) }\end{array}$ & $\begin{array}{c}\text { Elastisitas } \\
\text { Konsumen }\end{array}$ & $\begin{array}{c}\text { Persentase } \\
\text { PDRB/ Kapita (\%) }\end{array}$ \\
\hline 2018 & 188 & $17.829,74$ & 3,318263253 & $5,06 \%$ \\
2019 & 220 & $20.823,15$ & 3,318263253 & $5,06 \%$ \\
2020 & 256 & $24.319,12$ & 3,318263253 & $5,06 \%$ \\
2021 & 300 & $28.402,02$ & 3,318263253 & $5,06 \%$ \\
\hline 2022 & 350 & $33.170,39$ & 3,318263253 & $5,06 \%$ \\
\hline
\end{tabular}

Berdasarkan tabel di atas, akan ada kenaikan 117,27\% dalam konsumsi pemakaian energi oleh Segmen Industri hingga tahun 2022 mencapai 33.170,39 MWh.

\subsubsection{Segmen Umum}

Tabel 18. Proyeksi Kualitatif Sektoral di Segmen Umum

\begin{tabular}{|c|c|c|c|c|}
\hline & $\begin{array}{l}\text { Jumlah } \\
\text { Konsumen }\end{array}$ & $\begin{array}{l}\text { Kebutuhan Energi } \\
\text { (MWh) }\end{array}$ & $\begin{array}{l}\text { Elastisitas } \\
\text { Konsumen }\end{array}$ & $\begin{array}{c}\text { Persentase } \\
\text { PDRB/ Kapita (\%) }\end{array}$ \\
\hline 2018 & 100 & $7.182,03$ & 1,181274118 & $8,68 \%$ \\
\hline 2019 & 111 & $7.918,25$ & 1,181274118 & $8,68 \%$ \\
\hline 2020 & 122 & $8.729,94$ & 1,181274118 & $8,68 \%$ \\
\hline 2021 & 134 & $9.624,83$ & 1,181274118 & $8,68 \%$ \\
\hline 2022 & 148 & $10.611,45$ & 1,181274118 & $8,68 \%$ \\
\hline
\end{tabular}

Berdasarkan tabel di atas, akan ada kenaikan 62,9\% dalam konsumsi pemakaian energi oleh Segmen Industri hingga tahun 2022 mencapai 10.611,45 MWh.

\subsubsection{Segmen Perumahan}

Tabel 19. Proyeksi Kualitatif Sektoral di Segmen Perumahan

\begin{tabular}{|l|r|r|c|c|} 
& $\begin{array}{c}\text { Jumlah } \\
\text { Konsumen }\end{array}$ & $\begin{array}{r}\text { Kebutuhan Energi } \\
\text { (MWh) }\end{array}$ & $\begin{array}{c}\text { Elastisitas } \\
\text { Konsumen }\end{array}$ & $\begin{array}{c}\text { Persentase } \\
\text { PDRB/ Kapita (\%) }\end{array}$ \\
\hline 2018 & 2.494 & $9.111,70$ & 1,607368314 & $7,41 \%$ \\
2019 & 2.791 & $10.196,22$ & 1,607368314 & $7,41 \%$ \\
2020 & 3.123 & $11.409,84$ & 1,607368314 & $7,41 \%$ \\
2021 & 3.495 & $12.767,91$ & 1,607368314 & $7,41 \%$ \\
2022 & 3.911 & $14.287,62$ & 1,607368314 & $7,41 \%$ \\
\hline
\end{tabular}

Berdasarkan tabel di atas, akan ada kenaikan $75,47 \%$ dalam konsumsi pemakaian energi oleh Segmen Industri hingga tahun 2022 mencapai 14.287,62 MWh.

Dari hasil di atas didapatkan proyeksi pemakaian energi listrik hingga 2022 dapat dilihat pada gambar di bawah ini: 


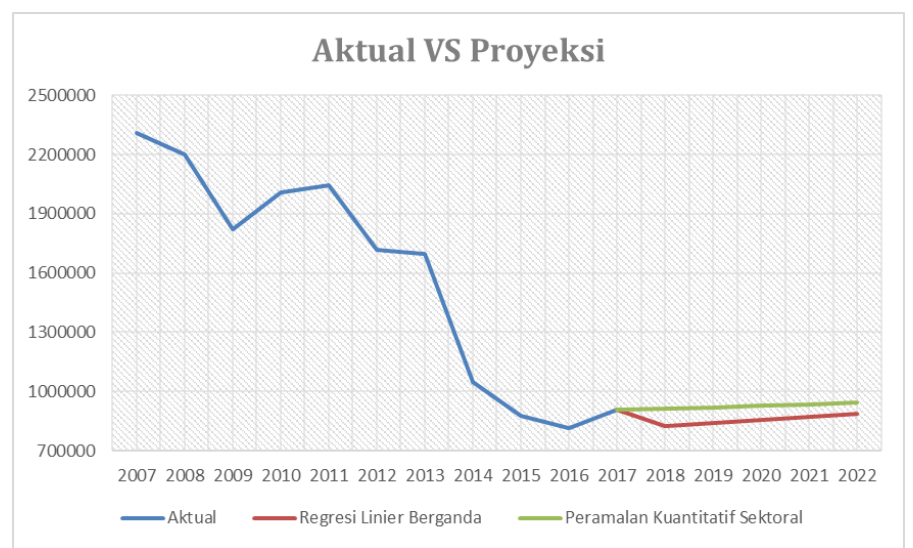

Gambar 3. Grafik Proyeksi Aktual vs Proyeksi

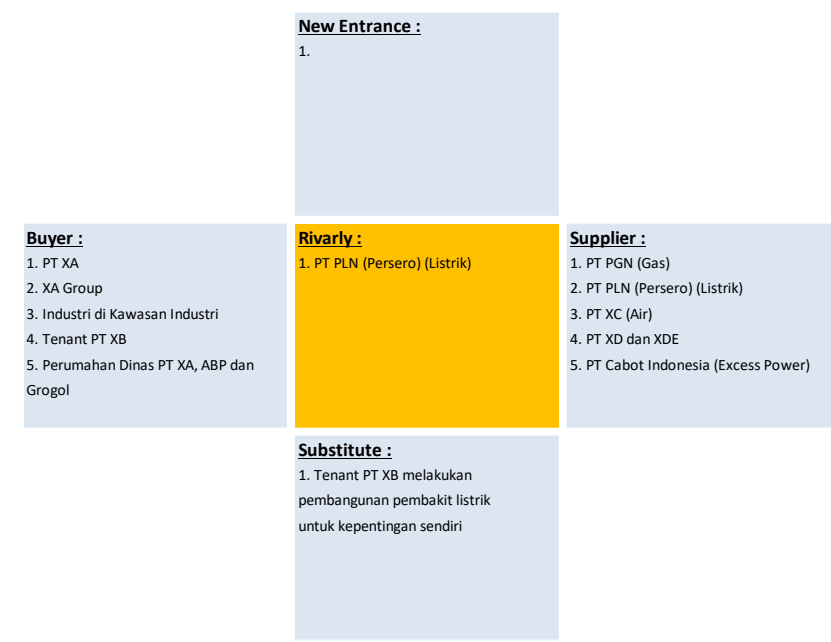

Gambar 4. Bagan Porters Five Forces

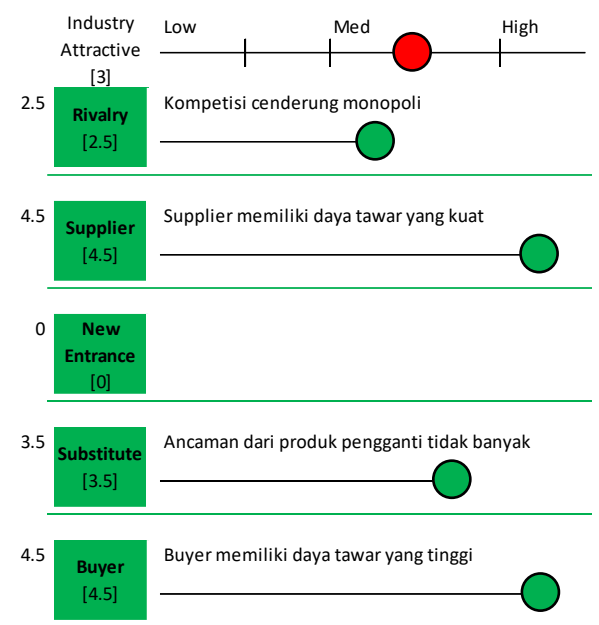

Dari penilaian disamping didapatkan rata - rata nilainya adalah 3 yang berarti "Industri Attractive" yang berarti Wilayah Usaha atraktif, dimana penyuplai memiliki daya tawar yang tinggi, cenderung monopoli, tanpa adanya pemain baru. Tetapi tetap waspada terkait regulasi dan pelayanan konsumen, karena sewaktu - waktu IUKU bisa dicabut ketika tidak lagi dapat meningkatkan kualitas.

Gambar 5. Bagan Penilaian Porter's Five Forces 


\section{KILAT}

Vol. 8, No. 2, Oktober 2019, P-ISSN 2089-1245, E-ISSN 2655-4925

Tabel 20. PESTLE Analysis

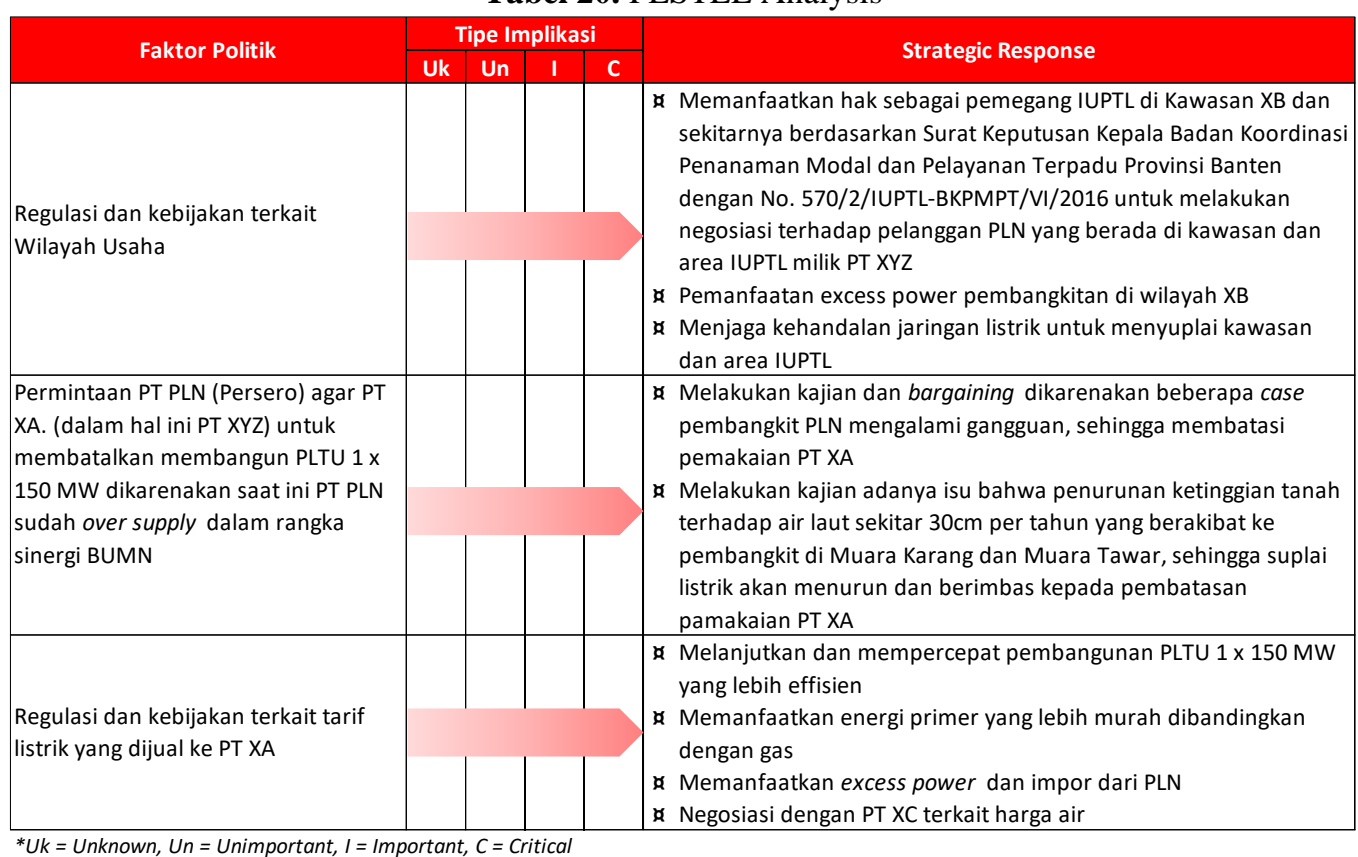

\begin{tabular}{|c|c|c|c|c|c|}
\hline \multirow{2}{*}{ Faktor Ekonomi } & \multicolumn{4}{|c|}{ Tipe Implikasi } & \multirow{2}{*}{ Strategic Response } \\
\hline & Uk & Un & I & $\mathrm{C}$ & \\
\hline Tarif listrik kompetitor & & & & & $\begin{array}{l}\text { Melakukan pembangunan pembangkit listrik yang lebih murah } \\
\text { biaya produksinya (PLTU, PLTA,dst) } \\
\text { Memanfaatkan excess power pembangkit di sisi konsumen } \\
\text { Mencari alternatif energi primer yang lebih murah }\end{array}$ \\
\hline $\begin{array}{l}\text { Kenaikan tingkat Upah Minimum } \\
\text { Karyawan (UMK) Kota Cilegon }\end{array}$ & & & & & $\begin{array}{l}\text { Meningkatkan produktivitas SDM dengan meningkatkan } \\
\text { kompetensi, memberikan gambaran kondisi perusahaan dan }\end{array}$ \\
\hline $\begin{array}{l}\text { Fluktuasi uncontrolable perubahan } \\
\text { kurs IDR terhadap USD }\end{array}$ & & & & & x Melakukan hedging kurs \\
\hline $\begin{array}{l}\text { Fluktuasi kenaikan harga energi } \\
\text { primer dan komoditas lain yang } \\
\text { berpengaruh kepada biaya produksi }\end{array}$ & & & & & $\begin{array}{l}\text { Meningkatkan effisiensi dan kehandalan pembangkit } \\
\text { Membuat kontrak jangka panjang kepada pemasok (supplier) } \\
\text { pembangkit }\end{array}$ \\
\hline Kenaikan suku bunga & & & & & $\begin{array}{l}\text { \. Mencari alternatif peminjaman dana dengan bunga rendah } \\
\text { × Melakukan kajian untuk melakukan IPO }\end{array}$ \\
\hline Pertumbuhan ekonomi & & & & & $\begin{array}{l}\text { Mengembangkan usaha penyediaan tenaga listrik dan jasa } \\
\text { kelistrikan } \\
\text { Mengoptimalkan penyuplaian energi listrik berdasarkan IUPTL } \\
\text { yang ada }\end{array}$ \\
\hline
\end{tabular}

*Uk $=$ Unknown, Un = Unimportant $I=I$ Important,$C=$ Critical

\begin{tabular}{|c|c|c|c|c|c|}
\hline \multirow{2}{*}{ Faktor Sosial } & \multicolumn{4}{|c|}{ Tipe Implikasi } & \multirow{2}{*}{ Strategic Response } \\
\hline & Uk & Un & 1 & $\mathrm{C}$ & \\
\hline $\begin{array}{l}\text { Meningkatnya populasi orang/ } \\
\text { penduduk }\end{array}$ & & & & & Peningkatan kapasitas untuk dapat menyuplai demand \\
\hline $\begin{array}{l}\text { Pembangunan pembangkit listrik baru } \\
\text { yang berdampak secara lingkungan }\end{array}$ & & & & & $\begin{array}{l}\text { Melakukan studi kelayakan (FS) terkait pengaruh terhadap sosial } \\
\text { sekitar } \\
\text { Koordinasi dengan pemerintah setempat dalam mengkaji risiko - } \\
\text { risiko sosial }\end{array}$ \\
\hline $\begin{array}{l}\text { Tingginya arus lalu lintas di kawasan } \\
\text { industri }\end{array}$ & & & & & Koordinasi dengan PT XB terkait mencari solusi masalah lalu lintas \\
\hline
\end{tabular}

${ }^{*} U k=$ Unknown, Un = Unimportant,$I=I$ Important $C=$ Critical 


\begin{tabular}{|c|c|c|c|c|c|}
\hline \multirow{2}{*}{ Faktor Technological } & \multicolumn{4}{|c|}{ Tipe Implikasi } & \multirow{2}{*}{ Strategic Response } \\
\hline & Uk & Un & $\mathrm{I}$ & C & \\
\hline $\begin{array}{l}\text { Perkembangan teknologi pembangkit } \\
\text { listrik yang semakin effisien }\end{array}$ & & & & & $\begin{array}{l}\text { Melakukan update knowledge SDM } \\
\text { Penerapan teknologi terbaru untuk meningkatkan effisiensi } \\
\text { pembangkit }\end{array}$ \\
\hline $\begin{array}{l}\text { Smart Grid yang sudah mulai } \\
\text { diterapkan di beberapa perusahaan }\end{array}$ & & & & & $\begin{array}{l}\text { Melakukan analisa keperluan penggunaan Smart Grid terhadap } \\
\text { investasi yang akan dikeluarkan }\end{array}$ \\
\hline $\begin{array}{l}\text { Berkembangnya peralatan predictive } \\
\text { maintenance }\end{array}$ & & & & & $\begin{array}{l}\text { Membeli peralatan seperlunya untuk mengurangi potensi } \\
\text { breakdown nya peralatan }\end{array}$ \\
\hline $\begin{array}{l}\text { Perkembangan peralatan yang } \\
\text { menimbulkan masalah baru }\end{array}$ & & & & & $\begin{array}{l}\text { Melakukan pengukuran THD } \\
\text { Melakukan review peralatan konsumen }\end{array}$ \\
\hline
\end{tabular}

${ }^{*} U k=$ Unknown, Un = Unimportant, I = Important, C = Critical

\begin{tabular}{|c|c|c|c|c|c|}
\hline \multirow{2}{*}{ Faktor Legal } & \multicolumn{4}{|c|}{ Tipe Implikasi } & \multirow{2}{*}{ Strategic Response } \\
\hline & Uk & Un & $\bar{I}$ & C & \\
\hline $\begin{array}{l}\text { Adanya regulasi sistem paralel } \\
\text { pembangkit listrik }\end{array}$ & & & & & Melakukan negosiasi dan kajian terhadap regulasi tersebut \\
\hline
\end{tabular}

Unknown, Un = Unimportant, $I=$ Important, $C=$ Critical

\begin{tabular}{|c|c|c|c|c|c|}
\hline \multirow{2}{*}{ Faktor Environment } & \multicolumn{4}{|c|}{ Tipe Implikasi } & \multirow{2}{*}{ Strategic Response } \\
\hline & Uk & Un & I & $\mathrm{C}$ & \\
\hline $\begin{array}{l}\text { Isu bahwa penurunan ketinggian } \\
\text { tanah terhadap air laut sekitar } 30 \mathrm{~cm} \\
\text { per tahun yang berakibat ke }\end{array}$ & & & & & \multirow[t]{2}{*}{ \& Melanjutkan dan menyegerakan pembangunan PLTU 1 x $150 \mathrm{MW}$} \\
\hline $\begin{array}{l}\text { Muara Tawar, sehingga suplai listrik } \\
\text { akan menurun dan berimbas kepada } \\
\text { pembatasan pamakaian PT XA }\end{array}$ & & & & & \\
\hline $\begin{array}{l}\text { Pembangunan PLTU } 1 \text { x } 150 \text { MW yang } \\
\text { lebih polutif dibandingkan PLTGU }\end{array}$ & & & & & $\begin{array}{l}\text { Melakukan kajian terhadap nilai NoX dan polusi yang diakibatkan } \\
\text { oleh PLTU dengan standar yang berlaku } \\
\text { Melakukan koordinasi dengan Dinas Kesehatan Lingkungan } \\
\text { terkait risiko apa saja yang berpengaruh akibat polusi yang } \\
\text { diakibatkan oleh PLTU }\end{array}$ \\
\hline
\end{tabular}

*Uk = Unknown, Un = Unimportant, $I=I$ mportant,$C=$ Critical

Tabel 21. SWOT Analysis

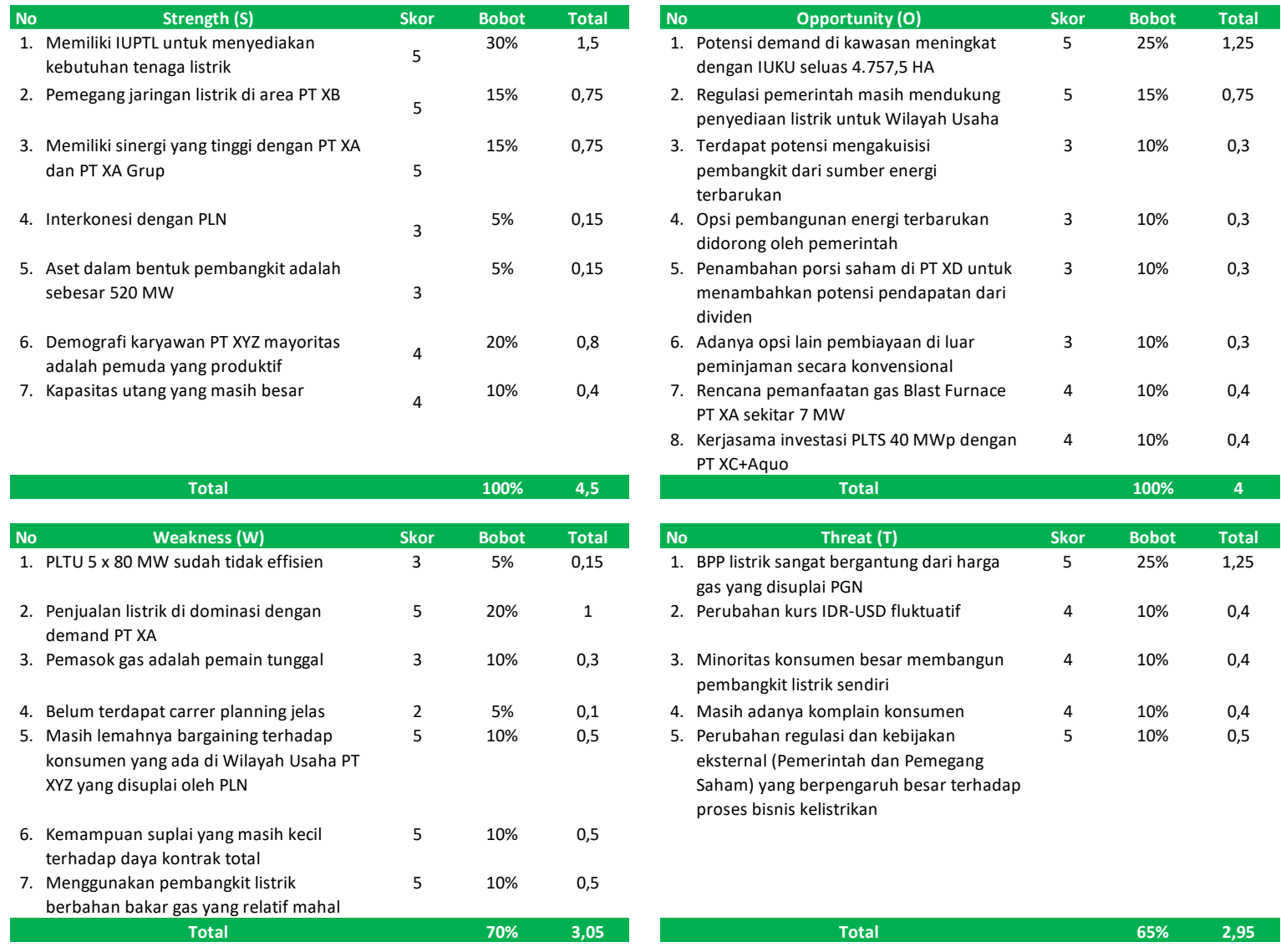




\section{KILAT}

Vol. 8, No. 2, Oktober 2019, P-ISSN 2089-1245, E-ISSN 2655-4925

Adapun penilaian SWOT analysis seperti tabel di atas menunjukkan bahwa penentuan nilai X adalah pengurangan antara (Strength - Weakness) dengan nilai 1,45 sedangkan Y adalah (Opportunities - Threat) dengan nilai 1,05. Dari hasil tersebut didapatkan bahwa PT XYZ masih dalam posisi kuadran 1 dengan strategi nya adalah Progressive. Lihat pada Gambar 7 dibawah ini:

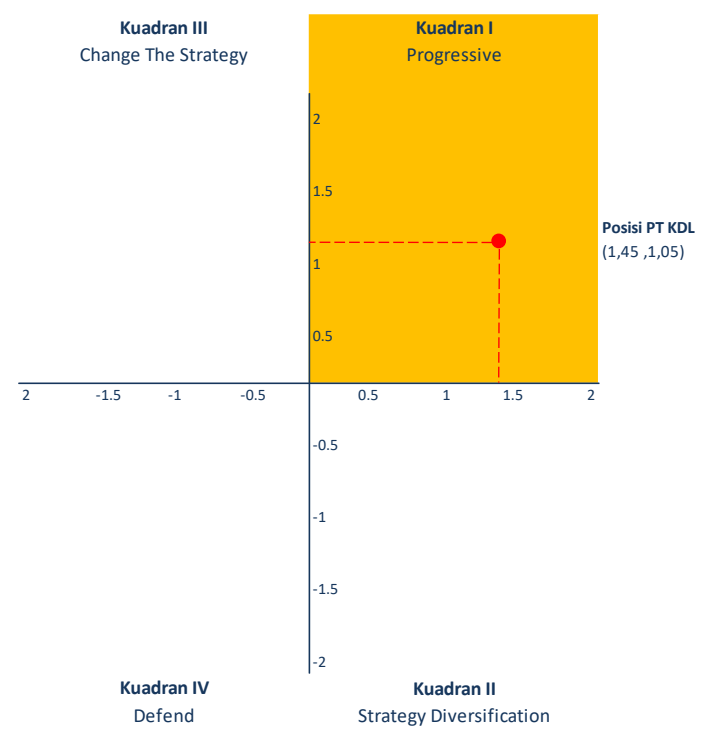

Gambar 6. Kuadran Posisi PT XYZ

\section{Keterangan}

\section{Kuadran I}

Posisi ini menunjukan sebuah organisasi yang kuat dan berpeluang. Rekomendasi strategi yang diberikan adalah "Progressive", artinya organisasi dalam kondisi prima dan mantap sehingga sangat dimungkinkan untuk terus melakukan ekspansi, memperbesar pertumbuhan dan meraih kemajuan.

\section{Kuadran II}

Posisi ini menunjukkan sebuah organisasi yang kuat namun menghadapi tantangan yang besar. Rekomendasi strategi ini adalah "Strategy Diversification" artinya organisasi dalam kondisi mantap namun menghadapi sejumlah tantangan berat sehingga diperkirakan roda organisasi akan mengalami kesulitan untuk terus berputar bila hanya bertumpu pada strategi sebelumnya. Oleh karena itu, organisasi disarankan untuk segera memperbanyak ragam strategi taktisnya.

\section{Kuadran III}

Posisi ini menunjukkan sebuah organisasi yang lemah namun sangat berpeluang. Rekomendasi strategi yang diberikan adalah "Change The Strategy" sebelumnya karena strategi yang lama dikhawatirkan sulit untuk dapat menangkap peluang yang ada sekaligus memperbaiki kinerja organisasi.

\section{Kuadran IV}

Posisi ini menunjukkan sebuah organisasi yang lemah dan menghadapi tantangan besar. Rekomendasi strategi yang diberikan adalah "Defend" artinya kondisi internal organisasi berada pada pilihan dilematis. Oleh karenanya organisasi disarankan untuk menggunakan strategi bertahan, mengendalikan kinerja internal agar tidak semakin terperosok. Strategi ini dipertahankan sambil terus berupaya membenahi diri. 


\section{KESIMPULAN DAN SARAN}

Berdasarkan hasil peramalan beban menggunakan analisa regresi linier berganda didapatkan bahwa terjadi penurunan dalam penyerapan energi listrik sebesar 824,252 GWh atau turun sebesar 9,1\% dari tahun 2017 dan dibandingkan dengan metode peramalan kuantitatif Sektoral $946 \mathrm{GWh}$ atau naik sebesar 4,3\% dari tahun 2017. Secara pembagian per segmen mengalami kenaikan 170,85 MWh tetapi dikarenakan PT XA sebagai konsumen terbesar dan merupakan pemilik saham PT XYZ yang mengalami penurunan mulai dari 2010 hingga 2017 sehingga secara total mengalami penurunan. Oleh karena itu melakukan kerjasama dengan pihak pengelola kawasan salah satu alternatif dalam melihat potensi perkembangan industri di sekitar agar tidak tergantung dengan PT XA, terlihat potensi dengan luas Kawasan yang tersisa adalah sebesar 35,15 MVA/ Ha dan Secara Analisa eksternal didapatkan bahwa bisnis PT XYZ masih atraktif dengan nilai rata-rata 3 pada penilaian Porter's Five Force's, secara Analisa internal menggunakan pemetaan SWOT Analysis PT XYZ masuk dalam kuadran I yang usulan strategi nya adalah "Progressive" yang artinya adalah posisi ini menunjukan sebuah organisasi yang kuat dan berpeluang. Organisasi dalam kondisi prima dan mantap sehingga sangat dimungkinkan untuk terus melakukan ekspansi, memperbesar pertumbuhan dan meraih kemajuan. agar dapat suistainable dalam berbisnis, dengan mengayomi karyawan dan mengajak untuk melakukan ekspansi dan melakukan continues improvement.

\section{UCAPAN TERIMAKASIH}

Penulis mengucapkan terima kasih kepada Bapak Hakimul Batih, ST., MT., Ph.d selaku Pembimbing Utama yang telah banyak memberikan masukan, inspirasi maupun ide - ide dalam penyelesaian masalah yang dihadapi. Bapak Dr. Dhami Johar Damiri, M.SI, Martin ST, M.Sc, Ph. D dan Dr. Ir. Soetjipto Soewono, Dipl., GE selaku penguji dan pembimbing revisi tesis ini dengan masukan yang diberikan. Terima kasih juga kepada keluarga tercinta,Mamak, Bapak, Mama, Papa,Istri tercinta Quinzela Herany dan Anak pertama kami Muhammad Rasyaa Faizan Zefa, Gusri Ayu Farsa selaku kakak perempuan dan Fadhil Rhisnanda selaku adek ipar, karena dukungan dari kalian lah saya dapat dengan semangat menyelesaikan seminar dan tesis ini dan Teman - teman seperjuangan S2 Magister Teknik Elektro STT PLN, dimana kita sudah berjuang bersama dalam menyelesaikan studi kita, semoga persahabatan kita dapat terus digalakan.

\section{DAFTAR PUSTAKA}

[1] D. Soekartawi, Teori Ekonomi Produksi Dengan Pokok Bahasan Analisis Fungsi CobbDouglas, Jakarta: CV Rajawali, 1990.

[2] D. Suswanto, Sistem Distribusi Tenaga Listrik, Padang, 2009.

[3] "Free Management Ebooks," [Online].

[4] BPS Kota Cilegon, "Kota Cilegon Dalam Angka 2007," BPS Kota Cilegon, Cilegon, 2007.

[5] BPS Kota Cilegon, "Kota Cilegon Dalam Angka 2006," BPS Kota Cilegon, Cilegon, 2006.

[6] BPS Kota Cilegon, "Kota Cilegon Dalam Angka 2008," BPS Kota Cilegon, Cilegon, 2008.

[7] BPS Kota Cilegon, "Kota Cilegon Dalam Angka 2009," BPS Kota Cilegon, Cilegon, 2009.

[8] BPS Kota Cilegon, "Kota Cilegon Dalam Angka 2010," BPS Kota Cilegon, Cilegon, 2010.

[9] BPS Kota Cilegon, "Kota Cilegon Dalam Angka 2011," BPS Kota Cilegon, Cilegon, 2011.

[10] BPS Kota Cilegon, "Kota Cilegon Dalam Angka 2012," BPS Kota Cilegon, Cilegon, 2012.

[11] BPS Kota Cilegon, "Kota Cilegon Dalam Angka 2013," BPS Kota Cilegon, Cilegon, 2013.

[12] BPS Kota Cilegon, "Kota Cilegon Dalam Angka 2014," BPS Kota Cilegon, Cilegon, 2014.

[13] BPS Kota Cilegon, "Kota Cilegon Dalam Angka 2015," BPS Kota Cilegon, Cilegon, 2015. 


\section{KILAT}

Vol. 8, No. 2, Oktober 2019, P-ISSN 2089-1245, E-ISSN 2655-4925

[14] BPS Kota Cilegon, "Kota Cilegon Dalam Angka 2016," BPS Kota Cilegon, Cilegon, 2016.

[15] BPS Kota Cilegon, "Kota Cilegon Dalam Angka 2017," BPS Kota Cilegon, Cilegon, 2017.

[16] A. H. R. D. R. Syafriwel, Analisis Peramalan Kebutuhan Energi Listrik Provinsi Sumatera Utara Menggunakan Metode Peramalan Kuantitatif Sektoral, 2015.

[17] A. R. Antonov, Prakiraan dan Analisa Kebutuhan Energi Listrik Provinsi Sumatera Barat Hingga Tahun 2024 Dengan Metode Analisis Regresi Linier Berganda, 2015.

[18] Bank Indonesia, "Infromasi Kurs : Bank Indonesia," 2018. [Online]. Available: https://www.bi.go.id/id/moneter/informasi-kurs/transaksi-bi/Default.aspx.

[19] L. Arsyad, Peramalan Bisnis, 2001.

[20] Krakatau Steel, "Annual Report 2006," Cilegon, 2006.

[21] Krakatau Steel, "Annual Report 2007," Cilegon, 2007.

[22] Krakatau Steel, "Annual Report 2008," Cilegon, 2008.

[23] Krakatau Steel, "Annual Report 2009," Cilegon, 2009.

[24] Krakatau Steel, "Annual Report 2010," Cilegon, 2010.

[25] Krakatau Steel, "Annual Report 2011," Cilegon, 2011.

[26] Krakatau Steel, "Annual Report 2012," Cilegon, 2012.

[27] Krakatau Steel, "Annual Report 2013," Cilegon, 2013.

[28] Krakatau Steel, "Annual Report 2014," Cilegon, 2014.

[29] Krakatau Steel, "Annual Report 2015," Cilegon, 2015.

[30] Krakatau Steel, "Annual Report 2016," Cilegon, 2016.

[31] Krakatau Steel, "Annual Report 2017," Cilegon, 2017.

[32] Sukmajati, S., \& Hafidz, M. (2015). Perancangan Dan Analisis Pembangkit Listrik Tenaga Surya Kapasitas $10 \mathrm{Mw}$ On Grid Di Yogyakarta. Energi \& Kelistrikan, 7(1), 49-63. https://doi.org/10.33322/energi.v7i1.582

[33] Yogianto, A., Hajar, I., \& Azzahra, S. (2018). Pemodelan Pembangkit Listrik Fotovoltaik Yang Terhubung Ke Jaringan. KILAT, 7(2), 201-209. https://doi.org/10.33322/kilat.v7i2.363

[34] Hasanah, A., Hariyati, R., \& Qosim, M. (2019). Konsep Fotovoltaik Terintegrasi On Grid dengan Gedung STT PLN. Energi \& Kelistrikan, 11(1), $17 \quad-\quad 26$. https://doi.org/10.33322/energi.v11i1.394 